\title{
FACTORS RELATED TO USE OF PRENATAL SCREENING TESTS AT HANOI OBSTETRICS AND GYNECOLOGY HOSPITAL IN 2021
}

\author{
Ha Thi Thu Hien', Le Thanh Tung ${ }^{2}$ \\ ${ }^{1}$ Hanoi Obstetrics and Gynecology Hospital ; ${ }^{2}$ Nam Dinh University of Nursing
}

\section{ABSTRACT}

Purpose: To examine the rate of use of prenatal screening tests and the factors related to the use of prenatal screening tests in pregnant women at Hanoi Obstetrics and Gynecology Hospital. Participants and methods: A cross-sectional descriptive study was performed on 350 pregnant women who came for prenatal screening at Hanoi Obstetrics and Gynecology Hospital. Results: $62 \%$ of pregnant women performed fetal ultrasound; $59.1 \%$ used Double test. $20.6 \%$ and $28.6 \%$ of pregnant women performed Triple test and NIPT. Only $25.4 \%$ of pregnant women used prenatal screening test according to the correct gestational age. The results indicated that the factors related to the use of the prenatal screening test included age, academic level, times of pregnance, previous results of screening tests, counseling. Specifically, the participants in the age group older than 30 years old, with a university degree or higher using the prenatal screening tests were higher at 5.26 times and 3.08 times compared to younger and lower educated participants. The participants with the second time or more of pregnance, risks from previous test results and counseled for prenatal screening tests using prenatal screening tests were 3.80 times, 3.22 times and 2.57 times compared to the participants with the first pregnancy, the previous normal test results, and without prenatal screening test counseling. Conclusion: These findings suggested that nurses and health care providers who are responsible for pregnant women should pay more attention to strengthen health education, timely counseling to raise awareness of pregnant women, especially in the group of pregnant women over 30 years old, with low education level, abnormal previous test results about the importance of prenatal screening tests, to help pregnant women make the right decisions to take the right prenatal screening tests in protecting the health of both mother and fetus.

Kyewords: Prenatal screening tests, pregnant women, Hanoi Obstetrics and Gynecology Hospital

\section{INTRODUCTION}

There are about 600 million disabled people in the world, of which nearly 5 million are disabled in Vietnam. The main cause of disability is birth defects, accounting for
$34.15 \%$ [1]. Statistics from the US Centers for Disease Control indicated that, annually, structural or genetic birth defects affected about $3 \%$ of births in the US, being the main cause of death in infants and leading to billions of dollars in care costs [2], [3],
Cor. author: Ha Thi Thu Hien

Address: Hanoi Obstetrics and Gynecology Hospital

Email: minhhien2883@gmail.com
Received: Dec 15, 2021

Accepted: Feb 24, 2022

Published: Feb 25, 2022 
[4]. According to the results of a study by Tu Du Hospital in 2002, in Vietnam, 3\% of fetuses were also affected by birth defects. According to a 2010 report of Tu Du Hospital, Ho Chi Minh City, in 5,652 cases of prenatal screening, 728 cases of fetal abnormalities were detected, accounting for $13 \%$. The statistics in 2000 - 2001, the number of children with birth defects admitted to the National Children's Hospital accounted for $12.4 \%$ of the hospitalized children and $10.5 \%$ of the deaths [1]. Children born according to each type of malformation died immediately after birth or survive with longlife suffering to the child, the family and the society. Therefore, birth defects are now a problem that requires the intervention of the whole society, especially the obstetrics and gynecology sector. Studies indicated that over time the rate of birth defects being screened increased. Besides environmental and genetic factors, it is necessary to mention that the advancement of medicine has made the detection of birth defects more accurate and effective than before [5], [6]. Currently, the number of couples who have a need for prenatal screening tests is increasing, therefore, learning about the use of prenatal screening tests may provide information from which to have solutions to help perform better day-to-day services, and at the same time conduct necessary consulting programs for customers. Stemming from that purpose, we conducted a research topic: "factors related to use of prenatal screening tests at Hanoi obstetrics and gynecology hospital in 2021" with the following objectives: To examine the rate of use of prenatal screening tests and the factors related to the use of prenatal screening tests in pregnant women at Hanoi Obstetrics and Gynecology Hospital.

\section{PARTICIPANTS AND METHODS}

2.1. Participants Are pregnant women with gestational age from 10 weeks to 20 weeks using prenatal care services at Hanoi Obstetrics and Gynecology Hospital.

2.2. Setting: The research was conducted from December 2020 to June 2021 at the Serviced Obstetrics Department and Center for Prenatal Screening and Diagnosis - Hanoi Obstetrics and Gynecology Hospital.

2.3. Research design: Cross-sectional descriptive study.

\subsection{Sample size and sampling}

- Sample size

Applying the formula to calculate sample size for one ratio

$$
\mathrm{n}=\mathrm{Z}_{1-\alpha / 2}^{2} \frac{\mathrm{p}(1-\mathrm{p})}{(\varepsilon \mathrm{p})^{2}}
$$

In which:

$-Z_{1-\alpha / 2}^{2}=1,96$ (confidence level 95\%)

$-\varepsilon=0,15$ (margin of error)

- $p=0,384$ (rate of pregnant women performing the double test at Hanoi Obstetrics and Gynecology Hospital in 2016 [7].

Substituting into the formula, the sample was 273 participants. Finally, the researcher collected 350 pregnant women.

- Sampling: Select a systematic random sample based on the medical record number. 


\section{RESULTS}

Table 1. Demographic characteristics of the participants $(n=350)$

\begin{tabular}{|ccc|}
\hline Characteristics of the participants & $\mathbf{n}$ & $\%$ \\
\hline Age (years old) & 66 & 18,9 \\
$<25$ & 177 & 50,6 \\
$25-30$ & 107 & 30,6 \\
$>30$ & & \\
\hline Academic level & 72 & 20,6 \\
Under high school & 96 & 27,4 \\
High school/intermediate & 182 & 52 \\
\hline University and above & & \\
Job & 50 & 14,3 \\
Farmer/Worker & 62 & 17,7 \\
Business & 181 & 51,7 \\
Officer & 57 & 16,3 \\
\hline Other (free, housewife) & &
\end{tabular}

Table 1 indicated that half of the participants (50.6\%) were in the age group of 25-30 years; $52 \%$ had undergraduate and graduate degrees. The majority $(51.7 \%)$ hold the job of an employee or public servant.

Table 2. Information about the current participant's pregnancy $(n=350)$

\begin{tabular}{|c|c|c|}
\hline Characteristics & $\mathbf{n}$ & $\%$ \\
\hline Current gestational age (Mean \pm SD) & \multicolumn{2}{|c|}{$13,2 \pm 2,2$} \\
\hline$\leq 12$ weeks & 206 & 58,9 \\
\hline 13-16 weeks & 96 & 27,4 \\
\hline$>16$ weeks & 48 & 13,7 \\
\hline \multicolumn{3}{|l|}{ Number of previous pregnancies } \\
\hline Not pregnant yet & 200 & 57,1 \\
\hline 1 times & 96 & 27,4 \\
\hline 2 times & 54 & 15,4 \\
\hline \multicolumn{3}{|l|}{ The current pregnancy } \\
\hline Planned pregnancy & 287 & 82 \\
\hline Pregnancy as an accident & 63 & 18 \\
\hline
\end{tabular}




\begin{tabular}{|ccc|}
\hline Characteristics & $\mathbf{n}$ & $\%$ \\
\hline Results of previous prenatal test & & \\
Normal & 329 & 94 \\
Risk of malformations & 21 & 6 \\
\hline Get advice on prenatal screening tests & & \\
Yes & 276 & 78,9 \\
Not & 74 & 21,1 \\
\hline
\end{tabular}

The mean gestational age was $13.2 \pm 2.2$ weeks, with more than half ( $58.9 \%)$ being less than 12 weeks. $57.1 \%$ of pregnant women were pregnant for the first time. The majority of pregnant women had normal results of previous antenatal tests and were consulted for prenatal screening tests.

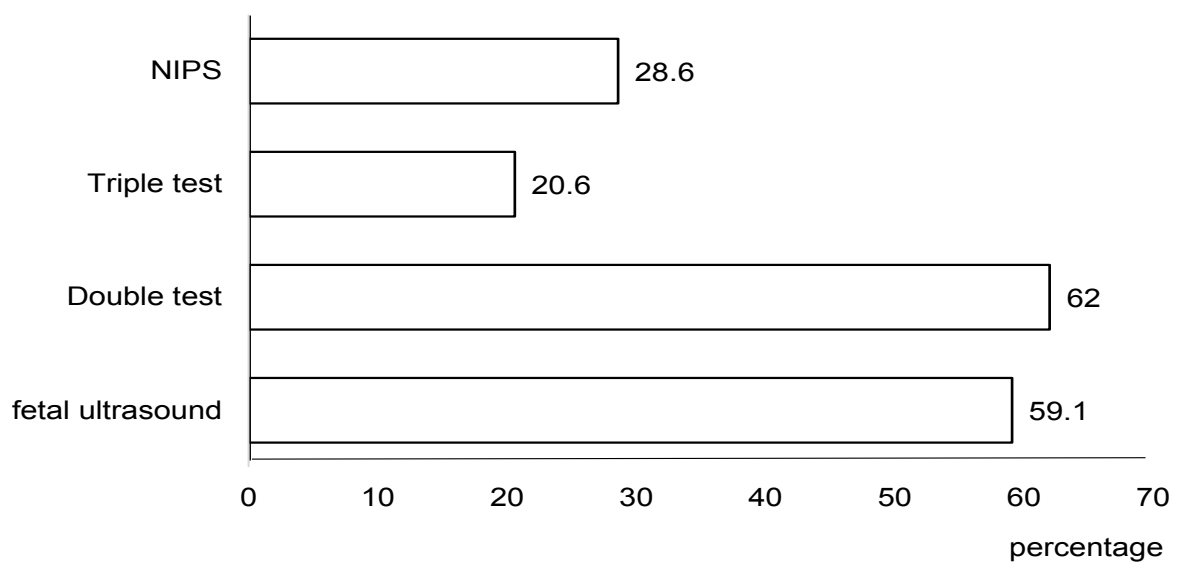

Figure 1. The rate of use of prenatal screening tests

Figure 1 indicated that more than half of pregnant women had a fetal ultrasound and used the Double test and were performed early. However, only $20.6 \%$ and $28.6 \%$ of pregnant women performed the Triple tests and NIPT.

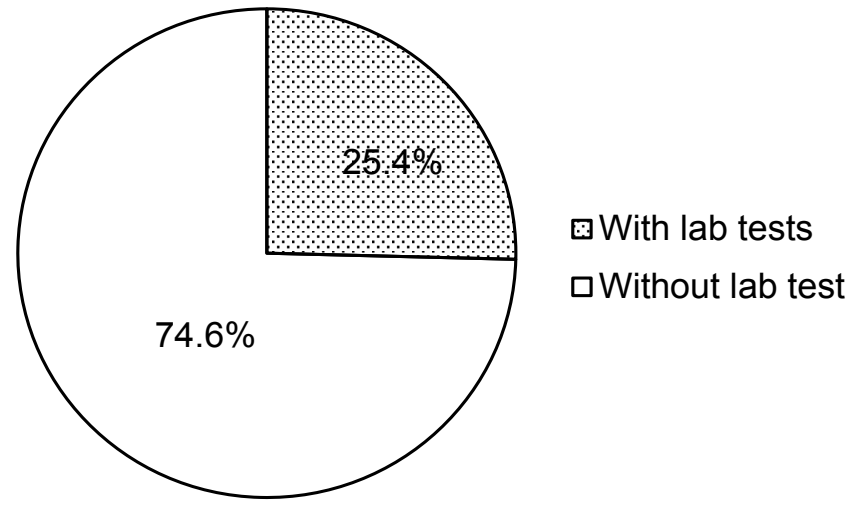

Figure 2. The rate of use prenatal screening test in the right gestational week

Figure 2 indicated that only $25.4 \%$ of participants used the prenatal screening tests according to the right gestational week. 
Table 3. The use of prenatal screening test of participants and related factors $(n=350)$

\begin{tabular}{|c|c|c|c|}
\hline \multirow[b]{2}{*}{ Characteritics } & \multicolumn{2}{|c|}{$\begin{array}{c}\begin{array}{c}\text { Use of prenatal screening } \\
\text { test }\end{array}\end{array}$} & \multirow{2}{*}{$\begin{array}{c}\text { OR } \\
(95 \% \mathrm{Cl})\end{array}$} \\
\hline & $\begin{array}{l}\text { Yes } \\
\text { n (\%) }\end{array}$ & $\begin{array}{c}\text { No } \\
\text { n (\%) }\end{array}$ & \\
\hline \multicolumn{4}{|l|}{ Age (years old) } \\
\hline$<25$ & $8(12,1 \%)$ & $58(87,9 \%)$ & 1 \\
\hline $25-30$ & $36(20,3 \%)$ & $141(79,7 \%)$ & $\begin{array}{c}1,85 \\
(0,81-4,25)\end{array}$ \\
\hline$>30$ & $45(42,1 \%)$ & $62(57,9 \%)$ & $\begin{array}{c}5,26 \\
(2,18-12,69)^{*}\end{array}$ \\
\hline \multicolumn{4}{|l|}{ Academic level } \\
\hline Under high school & $11(15,3 \%)$ & $61(84,7 \%)$ & 1 \\
\hline High school/intermediate & $13(13,5 \%)$ & $83(86,5 \%)$ & $\begin{array}{c}0,87 \\
(0,36-2,08)\end{array}$ \\
\hline University and above & $65(35,7 \%)$ & $117(64,3 \%)$ & $\begin{array}{c}3,08 \\
(1,49-6,37) \text { * }\end{array}$ \\
\hline \multicolumn{4}{|c|}{ Number of previous pregnancies } \\
\hline Not pregnacy yet & $37(18,5 \%)$ & $163(81,5 \%)$ & 1 \\
\hline 1 time & $27(28,1 \%)$ & $69(71,9 \%)$ & $\begin{array}{c}1,72 \\
(0,97-3,06)\end{array}$ \\
\hline$\geq 2$ times & $25(46,3 \%)$ & $29(53,7 \%)$ & $\begin{array}{c}3,8 \\
(1,95-7,41)^{*}\end{array}$ \\
\hline \multicolumn{4}{|c|}{ Results of previous prenatal test } \\
\hline Nornal & $73(22,2 \%)$ & $256(77,8 \%)$ & 1 \\
\hline Risk of malformations & $16(76,2 \%)$ & $5(23,8 \%)$ & $\begin{array}{c}3,22 \\
(1,78-5,28)^{*}\end{array}$ \\
\hline \multicolumn{4}{|c|}{ Get advice on prenatal screening tests } \\
\hline No & $10(18,8 \%)$ & $64(55,2 \%)$ & 1 \\
\hline Yes & $79(70,2 \%)$ & $197(205,8 \%)$ & $\begin{array}{c}2,57 \\
(1,24-5,29)^{*}\end{array}$ \\
\hline \multicolumn{4}{|c|}{$*: p<0,05$} \\
\hline
\end{tabular}

The results in Table 3 indicated that the factors related to the use of prenatal screening test were age group $>30$ years old $(\mathrm{OR}=5.26)$, academic level of Undergraduate/ Postgraduate $(\mathrm{OR}=3.08)$, pregnant 2 times $(\mathrm{OR}=3.8)$, the abnormal from the previous prenatal test results $(O R=3.22)$ and consulted for prenatal screening tests $(O R=2.57)$. 




Figure 3. Reasons for not using prenatal screening test $(n=261)$

When asked why pregnant women did not use prenatal screening tests, $109(41.8 \%)$ pregnant women reported that the test was expensive. 142 (54.4\%) pregnant women indicated that they were not clearly advised by healthcare providers which tests should conduct at previous visits. Only $3.8 \%$ of participants were worried about the tests affecting the fetus.

\section{DISCUSSION}

4.1. The rate of use of prenatal screening tests at Hanoi Obstetrics and Gynecology Hospital

In the study, half of the study participants $(50.6 \%)$ were between the ages of 25 and 30 years old. This rate was similar to the results of a study by Vasilis conducted in 2020 assessing the attitudes of 1170 pregnant women towards prenatal screening in Norway at the University Hospital of Oslo and the University Hospital of Akershus [8]. ]; Similar to the results of Tschudin's study conducted in Germany finding out the level of knowledge about prenatal screening among pregnant women, the average age in the study was $31.1 \pm 6.7$ years old [9]. This age was considered the best age in family building and family planning. According to Decision No. 588/ QD-TTG approved by the Prime Minister on April 28, 2020, on the birth rate adjustment program to regions and groups by 2030 , the State encouraged men and women to get married at 30 years old, should not marry late, and give birth early, women should give birth to a second child before age 35 . This was considered an important feature in order to firmly maintain the replacement of the birth rate nationwide, contributing to a successful Vietnam Population Strategy to 2030, ensuring rapid and sustainable development of the country [10].

The results showed that more than half of the pregnant women had pregnancy ultrasound, used the Double test, and performed the test early. This result was lower than the Vasilis study conducted in 2020 in Norway, where $86 \%$ of pregnant women admitted to using fetal ultrasound [8]. In the study, only $20.6 \%$ and $28.6 \%$ of pregnant women performed the Triple test and NIPT, similar to the study of Vasilis $(27.5 \%)$ [8]. The results of Tschudin's study conducted in Germany reported that the percentage of pregnant women using prenatal screening services was $76 \%$ [9], higher than in this study, only $89(25.4 \%)$ pregnant women used prenatal screening 
tests according to the right gestational week. Young pregnant women showed interest in their own pregnancy process from an early age, however, they did not conduct follow-up tests.

\subsection{Factors related to the use of prenatal screening tests at Hanoi Obstetrics and Gynecology Hospital}

The results showed that the factors related to the use of the prenatal screening test were age group above 30 years old $(\mathrm{OR}=5.26$; ); had a university/postgraduate education $(\mathrm{OR}=3.08)$; pregnancy more than 2 times $(\mathrm{OR}=3.8)$; pregnant women at risk from previous prenatal screening test $(\mathrm{OR}=3.22)$ and counseled for prenatal screening test $(\mathrm{OR}=2.57)$. This result was similar to the Vasilis study conducted in 2020 in Norway [8], when the place of birth, education level, religion and prenatal history were the factors that distinguished pregnant women with different attitudes towards prenatal screening. Katja's systematic review of 34 studies from 12 different countries found that a total of $88 \%$ of pregnant women considered their healthcare provider an important source of information and $57 \%$ said this information influenced their decisions in prenatal screening [11]. Or as the results of Vesna's study conducted in 2013 evaluating the attitudes and practices of Croatian pregnant women regarding prenatal screening tests showed similar results with the study. A total of 437 completed questionnaires were selected. Univariate regression analysis showed that age, education level and previously provided information were significant predictors for the decision of prenatal screening test of pregnant women [12].

In the study, about half of the participants reported they were not clearly advised by the health care provider which tests should be conducted at previous visits. Although there was no gold standard for what constitutes an adequate level of information for pregnant women about prenatal screening, some important consensus points were recommended screening conditions, features of screening tests, and explanations of possible test results. By understanding the needs of pregnant women as well as with timely and appropriate advice, healthcare providers may help pregnant women make the right decisions to conduct prenatal screening tests, protect their health both mother and fetus in the future.

This study was only a descriptive study, with small sample size, therefore, it only poses hypotheses but has not been tested. More predictive studies were needed to conduct for more accurate and effective. In fact, there were very few studies in Vietnam on the topic of assessing related factors, especially about the use of prenatal screening tests, this was a pretty big limitation of this study when there are not enough data sources to make comparisons.

\section{CONCLUSION}

These findings suggested that nurses and health care providers who are responsible for pregnant women should pay more attention to strengthening health education communication, timely counseling to raise awareness of pregnant women, especially in the group of pregnant women over 30 years old, with low education levels, abnormal prenatal test results about the importance of prenatal screening tests, to help pregnant women make the right decisions to conduct prenatal screening tests protecting their health, both mother and fetus in the future. 


\section{REFERENCES}

1. Bui Kim Chi (2014). Birth defects A problem of population quality. Population and development. Medical Publishing House, Hanoi.

2. Matthews T.J, MacDorman M.F, Thoma M.E. (2015). Infant Mortality Statistics From the 2013 Period Linked Birth/Infant Death Data Set. Natl Vital Stat Rep Cent Dis Control Prev Natl Cent Health Stat Natl Vital Stat Syst, 64(9), 1-30.

3. Centers for Disease Control and Prevention (CDC) (2008). Update on overall prevalence of major birth defects-Atlanta, Georgia, 1978-2005. MMWR Morb Mortal Wkly Rep, 57(1), 1-5. PubMed ID:18185492

4. USA CDC (2018). Data \& Statistics on Birth Defects. <https://www.cdc.gov/ ncbddd/birthdefects/data.html>, accessed: 01/01/2021.

5. Mai C.T, Isenburg J.L, Canfield M.A et al (2019). National population-based estimates for major birth defects, 20102014. Birth Defects Res, 111(18), 14201435. https://doi.org/10.1002/bdr2.1589

6. Xie D., Yang T., Liu Z et al (2016). Epidemiology of Birth Defects Based on a Birth Defect Surveillance System from 2005 to 2014 in Hunan Province, China. PloS One, 11(1), e0147280. https://doi. org/10.1371/journal.pone.0147280
7. Dinh Thi Linh (year 2016). The need of conducting the prenatal screening tests of double test, triple test and prenatal diagnosis of pregnant women at Hanoi Obstetrics and Gynecology Hospital in 2015 - 2016.

8. Sitras V., Ulriksen M., Benth J.Š. và cộng sự (2020). [Pregnant women's attitudes to prenatal screening in Norway]. Tidsskr Den Nor Laegeforening Tidsskr Prakt Med Ny Raekke, 140(14). DOI: 10.4045/tidsskr.20.0098

9. Tschudin S, Holzgreve W, Conde N et al (2009). Pregnant women's assessment and level of knowledge of prenatal counseling. Ultraschall Med Stuttg Ger 1980, 30(2), 157-162. DOI: 10.1055/s2008-1027383

10. Prime Minister (2020). Decision No. 588/QD-TTg dated April 28, 2020 approving on the birth rate adjustment program to regions and groups by 2030 .

11. Dahl K, Kesmodel U, Hvidman L et a (2006). Informed consent: attitudes, knowledge and information concerning prenatal examinations. Acta Obstet Gynecol Scand, 85(12), 1414-1419. https://doi. org/10.1080/00016340600985164

12. Kosec V, Zec I, Tislarić-Medenjak D et al (2013). Pregnant women's knowledge and attitudes to prenatal screening for fetal chromosomal abnormalities: Croatian multicentric survey. Coll Antropol, 37(2), 483-489. PMID: 23940994 